\title{
ANALISIS VIDEO COMMENTS TO VIEWERS RATIO YOUTUBE PADA 7 YOUTUBER WANITA KREATIF DAN POPULER DI INDONESIA
}

\author{
Yohana Sesilia Rita
}

$\underline{\text { Sesiliayohana31@gmail.com }}$

\section{ABSTRACK}

Youtuber is a video sharing website created by three former Paypal employees in February 2005. This website allows users to upload, watch and share videos. YouTube has become one of the most popular social media, and is a very large forum and opportunity for the world of marketing through content or videos uploaded by youtubers so that it can attract the attention of many viewers. The 7 Creatif and Popular Female YouTubers in Indonesia who use YouTube as a platform to create interesting content are : Sacha Stevenson, Natasha Farani, Rani Ramadhany, Ashilla, Dhana Xavier, Nadya cooking, and Fathia Izzati. The purpose of this study is to determine the credibility of the performance of the YouTube account 7 Creative and Popular Female YouTubers in Indonesia using the video Comments to Viewers Ratio. The method used for this research is quantitative exploratory method. The results of this study indicate that Sacha 
Stevenson's YouTube account is ranked first and has good account performance credibility.

\section{ABSTRAK}

Youtube merupakan sebuah situs web berbagi video yang dibuat oleh tiga mantan karyawan Paypal pada februari 2005. Situs web ini memungkinkan pengguna mengunggah, menonton, dan berbagi video. Youtube menjadi salah satu media sosial yang sangat popular, dan menjadi wadah dan peluang yang sangat besar untuk dunia marketing lewat konten atau video yang diunggah oleh youtuber sehingga bisa menarik perhatian banyak viewers. Adapun 7 Youtuber Wanita Kreatif dan Populer di Indonesia yang memanfaatkan youtube sebagai platform untuk membuat konten yang menarik yaitu : Sacha Stevenson, Natasha Farani, Rani Ramadhany, Ashilla, Dhana Xavier, Nadya cooking, dan Fathia Izzati. Tujuan dari penelitian ini adalah mengetahui kredibilitas performa dari akun YouTube 7 YouTuber Wanita Kreatif dan Populer di Indonesia menggunakan Video Comments to Viewers Ratio. Metode yang digunakan untuk penelitian ini yaitu metode eksploratif kuantitatif. Hasil dari penelitian ini menunjukan bahwa akun youtube Sacha Stevenson mendapatkan peringkat pertama dan memiliki kredibilitas performa akun yang baik.

Keywoard : Credibility Account Youtube ; Socal Media Marketing ; Social Media Youtube ; Video Comments to Viewers Ratio ; Youtuber Creative and Popular Indonesia 


\section{PENDAHULUAN}

Youtube merupakan salah satu media sosial dengan situs web yang menyediakan berbagai macam video mulai dari video clip, film serta video-video yang dibuat oleh pengguna youtube itu sendiri. Youtube ini sangat mudah untuk digunakan dan kini hadir diaplikasi ponsel seluler. Kita bisa menikmati media sosial ini dengan cara melihat video atau gambar yang bergerak. Youtube merupakan salah satu media sosial yang sangat popular dimasa sekarang. Sekarang banyak orang yang menggunakan youtube sebagai tempat berkarya dengan membuat video atau konten dan mereka disebut youtubers. Youtube menjadi salah satu media sosial yang sangat popular, dan menjadi wadah dan peluang yang sangat besar untuk berpenghasialn lewat konten atau video yang diunggah oleh youtuber sehingga bisa menarik perhatian banyak viewers.

Youtuber disebut sebagai istilah untuk pengguna youtube atau orang yang kreatif membuat video konten, konten yang berupa keseharian, comedy, berita maupun tutorial sehingga bisa menarik perhatian para viewers yang dapat menginspirasi, memberi motivasi, maupun ilmu pengetahuan yang bermanfaat bagi kalangan publik. Untuk membuat konten yang berkualitas harus memiliki persiapan yang matang. Banyak yang membuat conten video youtube sebagai 
pekerjaan sampingan atau bahkan hanya hobi. Berdasarkan jenis conten yang dibuatnya, youtuber memiliki gaya tersendiri yang memikat untuk dilihat oleh kalangan publik. Youtuber tersebut bisa banyak dikenal berdasarkan gaya pembawaan yang humoris atau memiliki karakteristik tersendiri atau dilihat dari tingkat popularitasnya. Adapun 7 YouTuber Wanita Kreatif dan Populer di Indonesia, diantarnya yaitu Sacha Stevenson, Natasha Farani, Rani Ramadhany, Ashilla, Dhana Xavier, Nadya cooking, dan Fathia Izzati.

Penelitian ini menggunakan metode eksploratif, dan akan menghitung menggunakan rasio-rasio yang ada pada YouTube. Penelitian ini hanya berfokus untuk menghitung kredibilitas Video Comments To Viewers Ratio pada 7 YouTuber Wanita Keatif dan Populer di Indonesia, diantaranya yaitu Sacha Stevenson, Natasha Farani, Rani Ramadhany, Ashilla, Dhana Xavier, Nadya cooking, dan Fathia Izzati. Tujuan dari penelitian ini adalah mengetahui kredibilitas performa dari akun YouTube 7 YouTuber Wanita Kreatif dan Populer di Indonesia menggunakan Video Comments to Viewers Ratio.

\section{TINJAUAN PUSTAKA}

Youtube merupakan sebuah aplikasi situs web video sharing (berbagi video) popular yang didirikan yang didirikan pada Februari 2005 oleh tiga orang bekas karyawan Paypal: Chad Hurley, Steven Chen, dan Jawed Karim. Youtube adalah database video yang paling popular didunia internet, atau 
bahkan mungkin yang paling lengkap dan variatif. Pada awalnya youtube memang bukan dikembangkan oleh Goegle, tapi Goegle mengakuisinya lalu kemudian menggabungkannya dengan layanan-layanan Goegle yang lain (Brad \& Debra dalam Kiftiyah 2009 : 201). Diperjelas Brad Debra (2009) dalam Kiftiyah menjelaskan Youtube ialah komunitas dimana seseorang mendapatkan hiburan, informasi, Pendidikan, serta inspirasi untuk saling berbagi menggunakan video secara online. Jadi youtube adalah aplikasi yang memudahkan pengguna dengan berbagai konten yang ada didalamnya, baik itu berupa hiburan, Pendidikan, komedi, berita dan vlog yang dapat diakses oleh berbagai kalangan secara online.

Sebagai platform berbagi video, saat ini YouTube tak sekedar tempat untuk mengunggah vlog ataupun daily life video. Lebih dari itu, YouTube merupakan salah satu media sosial yang banyak digunakan oleh brand dalam penerapan digital marketing business. Alasannya, YouTube dinilai mampu membangun brand awareness dan menjangkau konsumen yang lebih luas. Hal ini didasari oleh kegemaran generasi milenial yang lebih senang menyaksikan tayangan video di YouTube dibandingkan menonton acara televisi.

Menurut data dari Statista, YouTube sudah memiliki lebih dari 2 miliar pengguna aktif per bulannya. Sekitar 400 jam video diunggah ke YouTube dalam hitungan menit dan lebih dari satu miliar jam video ditonton di Platform ini setiap harinya. Artinya, ini adalah kesempatan besar bagi para 
pebisnis untuk menjangkau hingga $90 \%$ pelanggan yang akan menemukan produk atau brand mereka dari platform ini. Maka tak heran, jika saat ini sudah ada lehih dari $62 \%$ bisnis yang menggunakan video marketing di YouTube sebagai sarana digital marketing strategist mereka.

YouTube memiliki kekuatan yang berpengaruh dalam dunia industry, sehingga menimbulkan kualitas akun yang menentukan strata maupun kredibilitas pemilik akun. Kredibilitas akun YouTube merupakan suatu hal yang cukup penting untuk berbagai kepentingan. Kredibilitas sebuah akun YouTube dapat diukur dari tingkat performa yang dihasilkan secara matematis. Dalam mengukur performa diperlukan skala pengukuran yang tertuang ke dalam rasio.

\section{METODE PENELITIAN}

Jenis metode penelitian yang digunakan adalah metode penelitian eksploratif. Penelitian eksploratif adalah salah satu jenis penelitian yang tujuannya untuk memberikan defenisi atau penjelasan tentang kredibilitas dari akun youtube 7 Youtubers Wanita Kreatif dan Populer di Indonesia.

Tujuan dari penelitian ini adalah mengetahui kredibilitas dari performa akun youtube 7 Youtuber Wanita Kreatif dan Populer di Indonesia. Ada beberapa langkah yang harus dilakukan dalam penelitian ini, sehingga mampu menemukan peringkat pertama akun youtube 7 Youtuber Wanita Kreatif 
dan Populer di Indonesia yang memiliki performa terbaik. Langkah-langkah yang dilakukan pada penelitian ini adalah sebagai berikut:

1. Melakukan Eksplorasi Pada Website Untuk Menentukan Objek Yang Akan Dianalisa Eksplorasi ini dilakukan pada beberapa halaman website yang menyediakan informasi mengenai objek yang akan diteliti. Setelah eksplorasi selesai dilakukan, sehingga ditemukan nama-nama youtubers di Indonesia yang akan dijadikan objek analisa. Setelah melakukan eksplorasi pada halaman website, maka langkah selanjutnya yaitu mencari nama akun youtube dari masing-masing youtubers.

2. Menghitung Nilai Rata-Rata Variabel Dari 7 Youtubers Wanita Kreatif dan Populer di Indonesia Pada langkah ini, peneliti menghitung nilia variable video comments to viewers. Variable ini merupakan comments to viewers yaitu dengan cara mengambil 10 postingan kemudian dihitung sehingga menemukan nilai rata-rata dari masing-masing variable.variable yang memiliki nilai variasi dimana nilai tersebut dapat sebagai dasar untuk empat data yang berbeda seperti rasio, skala,ordinal, nominal dan internal. Untuk menghitung nilai rata-rata dari masing-masing variable. 


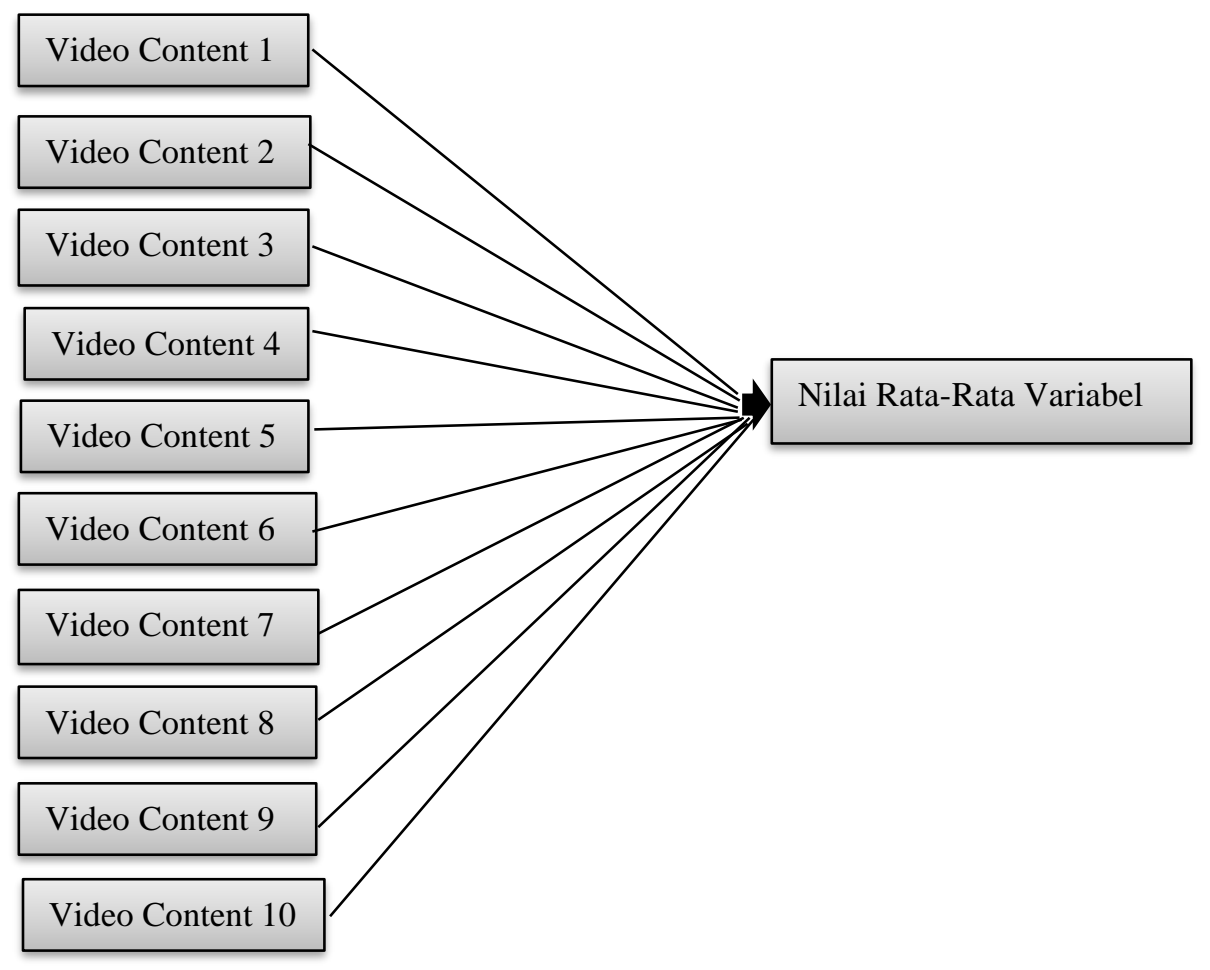

3. Menghitung Nilai Kredibilitas Rasio

Untuk menghitung nilai kredibilitas dari video comments to viewers ratio, peneliti menggunakan cara membagi nilai variabel pertama dengan nilai variabel kedua. Jika video comments memiliki nilai 100 dan video views memiliki nilai 300, maka cara menghitungnya yaitu $100: 300=0,3$. Dengan begitu nilai dari video comments to viewers ratio adalah 0,3 . 
4. Menentukan Peringkat Pada Akun TikTok

Pada langkah terakhir yang dilakukan pada penelitian ini yaitu menentukan peringkat pada masing-masing rasio yang ada. Pada penentuan peringkat perlu melihat karakteristik dari rasio yang di teliti. Jika karakteristik rasio merupakan rendah, maka objek yang memiliki nilai terendah akan mendapatkan angka 7 dan objek yang memiliki nilai tertinggi akan mendapatkan angka 1. Namun jika rasio memiliki karakteritik tinggi maka objek yang mendapatkan nilai tinggi akan mendapatkan angka 7 dan objek yang mendapatkan nilai terendah akan mendapatkan angka 1. Setelah mendapatkan hasil kredibilitas ratio maka dapat disimpulkan objek yang mana mendapatkan peringkat 1 sampai dengan peringkat 7 .

\section{HASIL DAN PEMBAHASAN}

Akun YouTube dari 7 YouTuber Wanita Kreatif dan Populer di Indonesia 


\section{Sacha Stevenson}

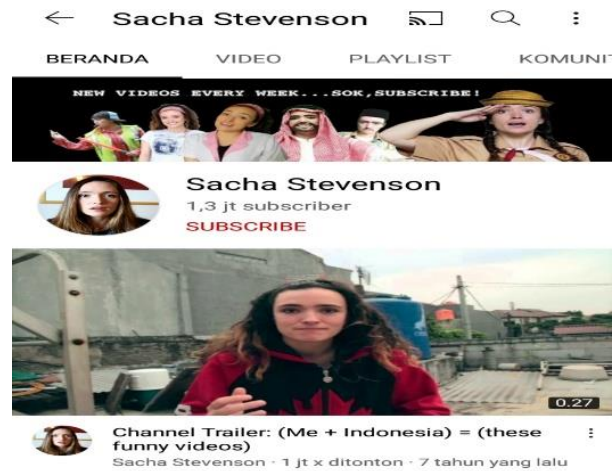

Gambar 1 akun YouTuber Sacha Stevenson

Sumber : https://youtube.com/c/SachaStevenson

\section{Natsha Farani}

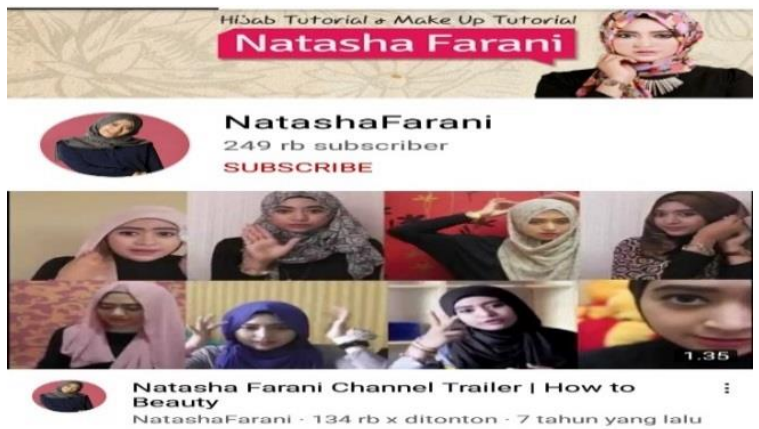


Gambar 2 akun YouTuber Natasha Farani

Sumber : https://youtube.com/c/NatashaFarani

\section{Rani Ramadhany}

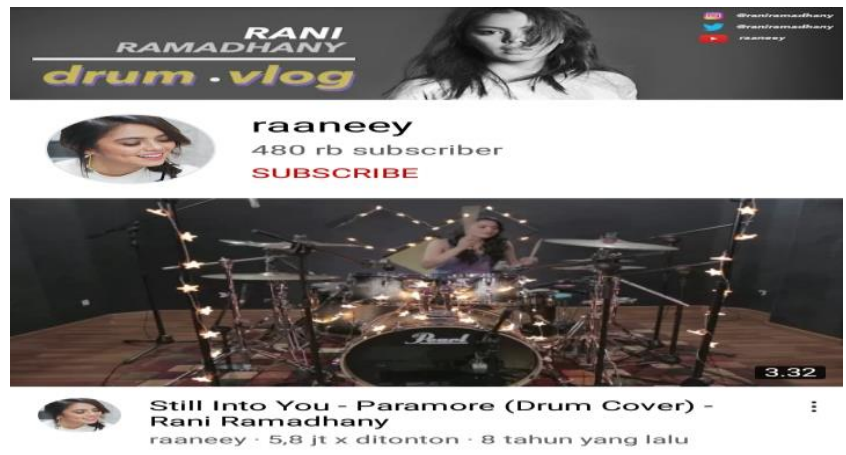

Gambar 3 akun YouTuber Rani Ramadhany

Sumber : https://youtube.com/user/raaneey

4. Ashilla 

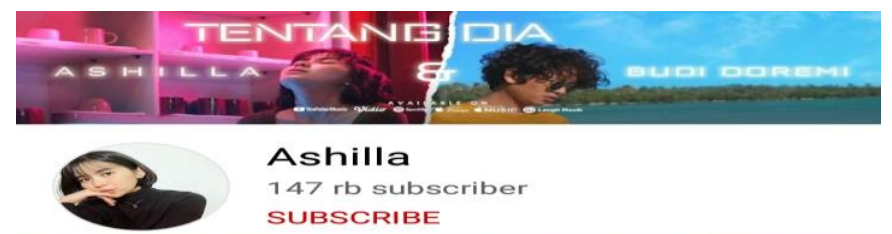

\section{Ashilla}

147 rb subscriber

SUBSCRIBE
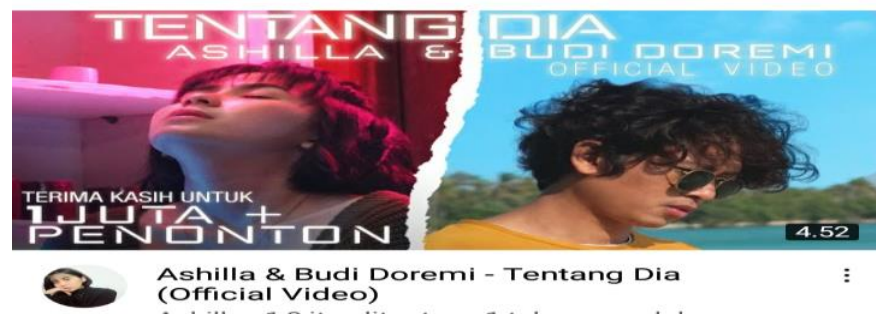

Ashilla - 1,9 jt $\times$ ditonton - 7 tahun yang lalu

Gambar 4 akun YouTuber Ashilla

Sumber : https://youtube.com/c/ashillatv

5. Dhana Xaviera
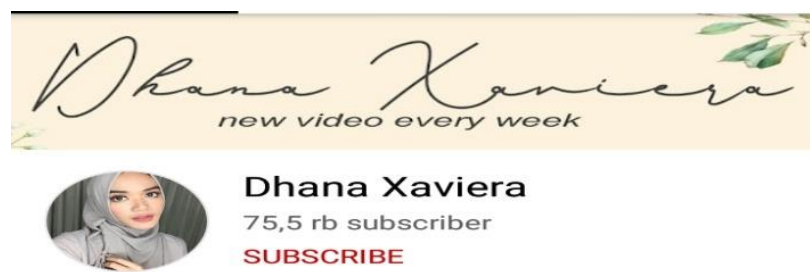

\section{Dhana Xaviera}

75,5 rb subscriber

SUBSCRIBE

\section{Upload populer}

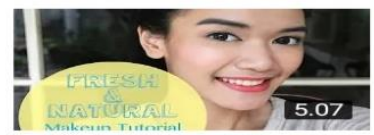

Gambar 5 akun YouTuber Dhana Xaviera 
Sumber : https://youtube.com/c/DhanaXaviera

\section{Nadya Cooking}
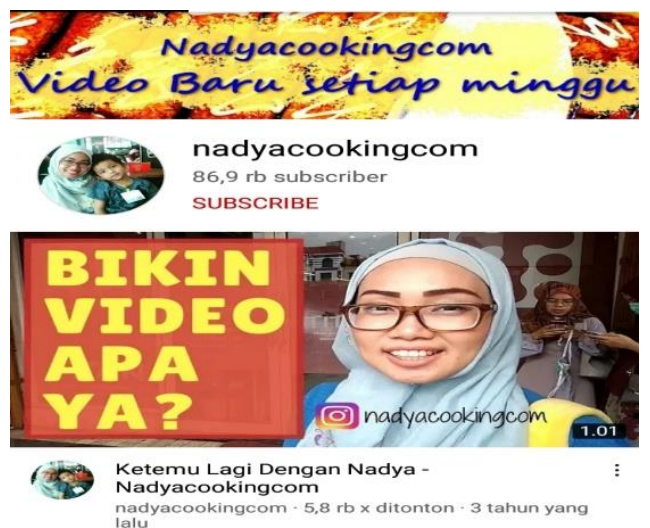

Gambar 6 akun YouTuber Nadya Cooking.

Sumber https://youtube.com/c/nadyacookingcom 


\section{Fathia Izzati}

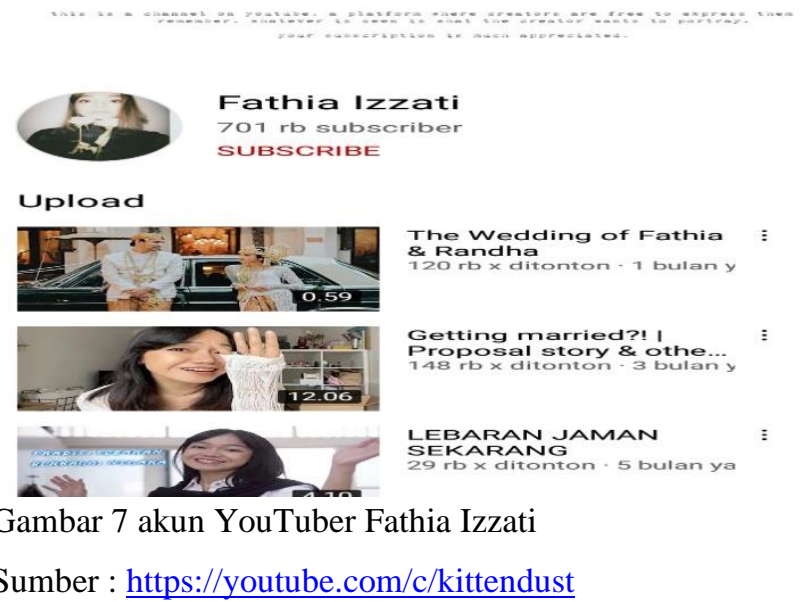

Dari ketujuh akun YouTube 7 YouTuber wanita Kreatif dan Populer di Indonesia peneliti menemukan masing-masing variabel yang ada untuk menghitung rasio video comments to viewers ratio youtube pada 7 youtuber wanita kreatif dan populer di Indonesia.

Pada akun youtube terdapat 6 variabel diantaranya yaitu:

\section{Variabel Post}

1. Variabel Subscriber

2. Variabel likes

3. Variabel Dislike

4. Variabel Viewers

5. Variabel Comments 
Dari keenam variabel tersebut peneliti hanya fokus menemukan hasil dari dua variabel yaitu :

1. Video comments

2. Video views

Dari kedua variabel tersebut kemudian dianalisa sehingga menemukan nilai rata-rata dari variabel video comments dan variabel video views. Untuk menghitung nilai ratarata dari video comments dan video views yaitu dengan cara mengambil minimal 10 postingan kemudian dihitung sehingga menemukan nilai rata-rata dari masing-masing variabel. Berikut merupakan tabel nilai rata-rata dari masing-masing YouTuber wanita kreatif dan Populer di Indonesia, yaitu:

Tabel 1. Analisa Nilai Rata-Rata Nilai Variabel Video Comments to Viewers Ratio Akun Youtube Sacha Stevenson

Sacha Stevenson

\begin{tabular}{|c|r|r|}
\hline No & Video Comments & Viewers Ratio \\
\hline 1 & 101,000 & 117,000 \\
\hline 2 & 1,000 & 6,400 \\
\hline 3 & 1,500 & 228,000 \\
\hline 4 & 1,600 & 185,000 \\
\hline 5 & 1,100 & 181,000 \\
\hline Total & $\mathbf{1 0 6 , 2 0 0}$ & $\mathbf{7 1 7 , 4 0 0}$ \\
\hline
\end{tabular}


Tabel 2. Analisa Nilai Rata-Rata Variabel Video Comments to Viewers Ratio Akun Youtube

Natasha Farani

Natasha Farani

\begin{tabular}{|c|r|r|}
\hline No & Video Comments & \multicolumn{1}{c|}{ Viewer Ratio } \\
\hline 1 & 45 & 13,000 \\
\hline 2 & 13 & 11,000 \\
\hline 3 & 80 & 52,000 \\
\hline 4 & 672 & $6,300,000$ \\
\hline 5 & 193 & 330,000 \\
\hline Total & 1003 & $6,706,000$ \\
\hline
\end{tabular}

Tabel 3. Analisa Nilai Rata-Rata Variabel Video Comments to Viewers Ratio Akun Youtube Rani Ramadhany

Rani Ramadhany

\begin{tabular}{|c|c|c|}
\hline No & Video Comments & Viewers Ratio \\
\hline 1 & 3,800 & $5,800,000$ \\
\hline 2 & 55 & 25,000 \\
\hline 3 & 141 & 16,000 \\
\hline 4 & 266 & 62,000 \\
\hline 5 & 154 & 15,000 \\
\hline Total & 4,416 & $5,918,000$ \\
\hline
\end{tabular}


Tabel 4. Analisa Nilai Rata-Rata Vriabel Video Comments to Viewers Ratio Akun Youtube Ashilla

Ashila

\begin{tabular}{|c|l|r|}
\hline No & Video Comments & Viewers Ratio \\
\hline 1 & 3,600 & $1,900,000$ \\
\hline 2 & 66 & 14,000 \\
\hline 3 & 37 & 19,000 \\
\hline 4 & 34 & 10,000 \\
\hline 5 & 44 & 11,000 \\
\hline Total & $\mathbf{3 , 7 8 1}$ & $\mathbf{1 , 9 5 4 , 0 0 0}$ \\
\hline
\end{tabular}

Tabel 5. Analisa Nilai Rata-Rata Variabel Video Comments to Viewers Ratio Akun Youtube Dhana Xaviera

Dhana Xaviera

\begin{tabular}{|c|r|r|}
\hline No & Video Comments & Viewers Ratio \\
\hline 1 & 331 & $1,200,000$ \\
\hline 2 & 158 & $1,000,000$ \\
\hline 3 & 226 & 415 \\
\hline 4 & 272 & 389,000 \\
\hline 5 & 42 & 3,000 \\
\hline Total & $\mathbf{1 0 2 9}$ & $\mathbf{2 , 5 9 2 , 4 1 5}$ \\
\hline
\end{tabular}


Tabel 6 .Analisa Nilai Rata-Rata Variabel Video Comments to Viewers Ratio Akun Youtube Nadya cooking

Nadyacookingcom

\begin{tabular}{|r|l|r|}
\hline \multicolumn{1}{|l|}{ No } & Video Comments & \multicolumn{2}{|l|}{ Viewers Ratio } \\
\hline 1 & 23 & 2,600 \\
\hline 2 & 9 & 952 \\
\hline 3 & 0 & 1,300 \\
\hline 4 & 13 & 1,800 \\
\hline 5 & 7 & 826 \\
\hline Total & $\mathbf{5 2}$ & $\mathbf{7 , 4 7 8}$ \\
\hline
\end{tabular}

Tabel 7. Nilai Rata-Rata Variabel Video Comments to Viewers Ratio Akun Youtube Fathia Izzati

Fathia Izzati

\begin{tabular}{|c|r|r|}
\hline NO & Video Comments & \multicolumn{1}{|c|}{ Viewers Ratio } \\
\hline 1 & 550 & 118,000 \\
\hline 2 & 603 & 148,000 \\
\hline 3 & 99 & 28,000 \\
\hline 4 & 29 & 14,000 \\
\hline 5 & 46,000 & $13,000,000$ \\
\hline Total & $\mathbf{4 7 2 8 1}$ & $\mathbf{1 3 , 3 0 8 , 0 0 0}$ \\
\hline
\end{tabular}


Setelah menghitung nilai rata-rata tersebut maka akan menemukan hasil nilai rata-rata dari variabel video comments to viewers ratio.

Tabel 6. Nilai Variabel Pada Akun Youtube 7 Youtuber Wanita Kreatif dan Populer di Indonesia.

Total Viewers

\begin{tabular}{|l|r|}
\hline \multicolumn{1}{|c|}{ Youtuber } & \multicolumn{1}{c|}{ Viewers } \\
\hline Sacha Stevenson & 717,400 \\
\hline Natasha Farani & $6,706,000$ \\
\hline Rani Ramadhany & $5,918,000$ \\
\hline Dhana Xaviera & $2,592,415$ \\
\hline Ashila & $1,954,000$ \\
\hline Nadyacookingcom & 7,478 \\
\hline Fathia Izzati & $13,308,000$ \\
\hline
\end{tabular}

Note:

Variabel

1. Comments

2. Viewers

\section{Total Comments}

\begin{tabular}{|l|l|}
\hline \multicolumn{1}{|c|}{ Youtuber } & Comments \\
\hline Sacha Stevenson & 106,200 \\
\hline Natasha Farani & 1003 \\
\hline Rani Ramadhany & 4,416 \\
\hline Dhana Xaviera & 1029 \\
\hline
\end{tabular}




\begin{tabular}{|l|l|}
\hline Ashilla & 3,781 \\
\hline Nadyacookingcom & 52 \\
\hline Fathia Izzati & 47281 \\
\hline
\end{tabular}

Pada Penelitian kali ini hanya fokus untuk menghitung Video Comments to Viewers Ratio. Untuk menghitung kredibilitas dari masing-masing akun youtube dari 7 youtuber wanita kreatif dan dan populer, peneliti menghitung dengan cara variabel 1 akan dibagi dengan variabel 2 sehingga ditemukan hasil analisa dari rasio tersebut.

Tabel 9. Hasil Perhitungan Rasio Akun Youtube

\begin{tabular}{|l|l|l|l|l|l|l}
\hline NO & \multicolumn{1}{|l|}{ Ratio } & $\begin{array}{l}\text { Sacha } \\
\text { Stevenson }\end{array}$ & $\begin{array}{l}\text { Natasha } \\
\text { Farani }\end{array}$ & $\begin{array}{l}\text { Rani } \\
\text { Ramadhany }\end{array}$ & $\begin{array}{l}\text { Dhana } \\
\text { Xaviera }\end{array}$ & Ashila \\
\hline $\begin{array}{l}\text { Video } \\
\text { Comments } \\
\text { to viewers } \\
\text { ratio }\end{array}$ & 0.148034569 & 0.000149568 & 0.000746198 & 0.000396927 & 0.001935005 \\
\hline
\end{tabular}

\begin{tabular}{r|r|c|}
\hline Nadyacookingcom & Fathia Izzat & \multirow{2}{*}{ Karateristik } \\
\cline { 1 - 2 } 0.006953731 & 0.003552825 & Tinggi \\
\hline
\end{tabular}


Video comments to viewers ratio memiliki karakteristik yang tinggi, artinya semakin tinggi nilai yang dihasilkan maka semakin baik kredibilitas dari performa akun tersebut. Untuk memberikan peringkat pada masing-masing 7 youtuber peneliti memberikan angka 7 kepada vendor yang mendapatkan nilai tertinggi dan angka 1 untuk vendor youtuber yang mendapatkan nilai terendah. Berikut merupakan tabel urutan nilai yang dihasilkan oleh masingmasing vendor youtuber.

Tabel 10. Nilain Rasio Akun Youtube 7 Youtuber Wanita Kreatif dan Populer di Indonesia

Table Peringkat Video Comments To Viewers Ratio

\begin{tabular}{|c|c|c|c|}
\hline Sacha Stevenson & Natasha Farani & Rani Ramadhany & Dhana Xaviera \\
\hline 7 & 1 & 3 & 2 \\
\hline
\end{tabular}

\begin{tabular}{|l|l|l|}
\hline Ashila & Nadyacookingcom & Fathia Izzat \\
\hline 4 & 6 & 5 \\
\hline
\end{tabular}

Kesimpulan:

Peringkat pertama $=$ Sacha Stevenson

Peringkat kedua = Nadyacookingcom

Peringkat ketiga $=$ Fathia Izzat

Peringkat keempat $=$ Ashila

Peringkat Kelima = Rani Ramadhany

Peringkat keenma $=$ Dhana Xaviera 
Peringkat ketujuh $=$ Natasha Farani

Dari tabel nilai rasio akun youtube pada 7 Youtuber Wanita Kreatif dan Populer di Indonesia dapat disimpulkan bahwa akun youtube Sacha Stevenson mendapatkan nilai tertinggi untuk ratio video comments to viewers ratio. Sedangkan akun youtube Natasha Farani mendapatkan nilai terendah untuk rasio ini. Jadi pada penelitian ini akun youtube Sacha Stevenson memiliki kredibilitas performa yang lebih baik dibandingkan dengan akun youtuber lainnya.

\section{KESIMPULAN}

Tujuan dari penelitian ini adalah mengetahui kredibilitas performa dari akun youtube 7 Wanita Kreatif dan Populer di Indonesia menggunakan video comments to viewers ratio. 7 Youtuber Wanita Kreatif dan Populer di Indonesia tersebut diantaranya:Sacha Stevenson, Natasha Farani, Rani Ramadhany, Ashilla, Dhana Xavier, Nadya cooking, dan Fathia Izzati. Dari ketujuh youtuber tersebut dapat disimpulkan bahwa :

1. Peringkat pertama diraih oleh Sacha Stevenson dengan nilai tertinggi yaitu 0,148034569

2. Peringkat kedua diraih oleh Nadya cooking dengan nilai 0,006953731 
3. Peringkat ketiga diraih oleh Fatia Izzati dengan nilai 0,003552825

4. Peringkat keempat diraih oleh Ashilla dengan nilai 0,01935005

5. Peringkat kelima diraih oleh Rani Ramadhany dengan nilai 0,000746198

6. Peringkat keenam diraih oleh Dhana Xaviera dengan nilai 0,000396927

7. Peringkat ketujuh diraih oleh Natasha Farani dengan nilai terendah 0,000149568 


\section{DAFTAR PUSTAKA}

https://id.m.wikipedia.org/wiki/YouTube https://penalaran-unm.org/penelitian-eksploratif/ http://digilib.ars.ac.id/index.php?p=fstreampdf \&fid $=4255 \&$ bid $=5684$ https://media.neliti.com/media/publications/93363-IDpengaruh-konten-vlog-dalam-youtube-terha.pdf 